\title{
Design and Process Analysis of Single Cavity Injection Molding Die for Plastic Wing Nut
}

\author{
Neeraj Kumar Jha ${ }^{1}$, G. Bharath Reddy ${ }^{2}$ and Vidyanand Kumar $^{3}$ \\ ${ }^{1}$ Assoc. Professor, CVR College of Engineering/ Mechanical Engg. Department, Hyderabad, India \\ Email: neerajjha.me@gmail.com \\ ${ }^{2}$ Asst. Professor, CVR College of Engineering/ Mechanical Engg. Department, Hyderabad, India \\ Email: gbreddymech@gmail.com \\ ${ }^{3}$ Asst. Professor, CVR College of Engineering/ Mechanical Engg. Department, Hyderabad, India \\ Email: vidyanadk75@gmail.com
}

\begin{abstract}
Material selection is an important step under active planning phase in production planning and control and, so is process selection. Polymers are preferable option for various products due to their desirable properties. Light weight, low cost, corrosion resistant and high strength to weight ratio is few among them. In similar manner injection molding is the most suitable process to be preferred for processing various grades of thermoplastics. The process preferably utilizes a heating unit to take polymers to their injection temperature, a permanent mold with shaped cavity as the shape of the required product along with clamping and cooling provisions. The process is best suitable for mass production of plastic parts and is widely used industrially. The permanent mold used in injection molding process is also referred as plastic mold. These molds must be designed and analyzed before their manufacturing to ensure suitability of the molding with particular plastic material type. This article attempts to ensure suitability of molding plastic wing nuts, an internal threaded component, by injection molding process with polypropylene (PP) and high density poly ethylene (HDPE) material. Modeling of parts is done with UG Nx 9.0 while the flow analysis is performed by Autodesk Mold Flow Adviser 2015.
\end{abstract}

Index Terms: Injection molding, permanent mold, internal threaded component, polypropylene, high density poly ethylene.

\section{INTRODUCTION}

Injection molding is commonly used method for manufacturing of plastic components with complex geometries [1]. This process is considered as one of the primary shaping process which utilizes a permanent mold along with injection molding machine. The four phases of injection molding processes are clamping, injection, cooling and ejection [2]. Clamping is about closing the split mold and holding it to withstand injection pressure. Injection is about pressurized filling of the mold cavity with plastic material at semisolid phase. It utilizes shot volume, the volume of material sufficient to fill all the cavities of die at once. Solidification of the filled cavity by transferring temperature to the mold walls is referred as cooling. Ejection is the process of removal of solidified component from permanent mold cavity after opening of the split mold. The process is simple to observe, operate and automate but it involves proper understanding, care and analysis of numerous parameters. These parameters must be analyzed well before the die manufacturing to prevent loss of time and money. The conventional approaches of obtaining correct die design adapted by industries, may affect quality of component as well as overall efficiency of the industry [3]. Suitable flow analysis software helps a designer to analyze and visualize the process control parameters for effective die design [4]. Researchers develop and compare the results from various mathematical models also, but the results obtained by software simulations are much convenient to visualize and understand for further design iterations [5]. As per current trend of eco-design, researchers are attempting to achieve sustainability in design phase [6]. There are many critical factors to take care, for the aim of getting a quality product economically and effectively. Injection temperature, flow rate, injection pressure and mold temperature are few independent variables of the process. Importance of fill time and solidification time also cannot be ignored as it directly affects the cycle time [7]. The process also depends on the processing material and its properties [8]. In the similar way, temperature variance, cooling time variance, pressure drop inside the mold etc. are also important parameters. With suitable software tool, not only the quality of product but defects like weld lines, air porosity, shrink cavities etc. also can be predicted. Researchers opined that the process parameters also affect the mechanical properties of the molded component [9].

Injection molding process can be compared with cold chamber die casting process [10]. Both the processes implement split mold, injection unit, cooling unit as well as provision of clamping. But the injection molding process has its unique advantage of molding threaded parts. Threaded profiles are not obtained by die casting process. Removal of threaded core is a difficult task and its accomplishment usually leads to broken thread profile in the component. Molten metal contracts along the helix of core, and relative movement of stiffer surfaces becomes difficult. Thus, in die casting cored holes are obtained with machining allowance. Further these cored holes of the ejected components are drilled and tapped to obtain the thread profile. But in the injection molding process obtaining threaded profiles is possible in the molding process itself. Inserts with thread profile is located at desired positions prior to injection. After injection, as usual plastic contracts on threaded profile but removal of these threaded inserts is easy and does not cause any damage to the thread profile of 
the component. Softness or flexibility of plastic is the reason. When threaded insert is unscrewed for removal, the contracted plastic slips over the metallic surface of insert. Thus, the insert removal becomes easy and the solidified component remains unharmed. The procedure leads to increased cycle time and higher tooling cost. With a suitable mold design, tooling cost can be kept low and the same may help for cycle time also [11].

This article aims at checking feasibility of injection molding of wing nut, a small mechanical element with internal thread. Usually, they are made of metal or thermosetting plastic with internal threaded insert. Metallic wing nuts are made by die casting followed by machining while polymer wing nuts are manufactured by transfer molding. This work attempts to see possibility of making wing nut by PP and HDPE. The process is analyzed by Autodesk Mold Flow Adviser and based on the obtained results, the validation of process is done by manufacturing a sample die.

\section{Product Design}

Proper product design is foundation of tool design. Suitability of mold design, analysis of process parameters and overall profitability of process depends on effective product design and its observation. Solid model for M10 wing nut considered for this work is shown in Fig.1. The part is modeled by providing sufficient fillets as per plastic molding design considerations.

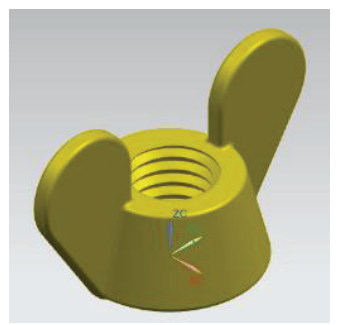

Figure 1. Wing Nut Solid Model

Dimensions were considered according to Metric DIN 315 standards. Drafting of the component is indicated in Fig.2. It is designed as per ISO metric left hand V thread with nominal diameter $10 \mathrm{~mm}$. as per product design considerations for injection molding part one must ensure sufficient fillet and draft in the component. Fillet helps in proper filling of the mold cavity and reduces stress concentration in the component. Purpose of draft is to ensure proper ejection of the component from the mold cavity as it is provided on the faces in the direction of ejection. Proper observation of component is necessary as it helps in understanding requirement of draft, presence of undercuts, requirement of side core etc. Economical and easy manufacturing of die is another obvious advantage of such observations. From the observation of the component it is clear that there is requirement of a threaded side insert for shaping of internal thread profile. Direction for movement of side insert must also be planned along with direction of split opening of two halves of the die. Usually side cores are actuated along the parting plane.

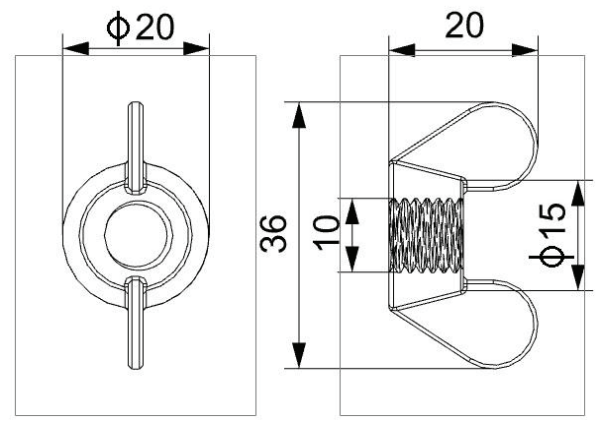

Figure 2. Wing Nut Drafting

(All dimensions are in $\mathrm{mm}$ )

After proper study of the component, it is finalized that mold should open in the direction perpendicular to placement of wings, thus parting plane is spread along wings of the wing nut. The advantage of taking parting plane in this orientation is that there is no need of considering draft and comparatively less deep cavity will be machined in mold, thus easy to machine and later convenient for the ejection of the component. The placement of parting plane and the direction of movement of side core is indicated in Fig.3. It can be understood from this figure that the mold halves will split in the direction perpendicular to parting plane and the direction of movement of the threaded insert is along the parting plane.

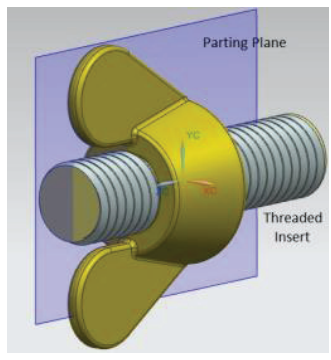

Figure 3. Wing Nut Drafting

The curve and taper profile of nut body represents no use of draft, thus there is no need of draft analysis of the component. Thick mass analysis of the component is represented in Fig.4.

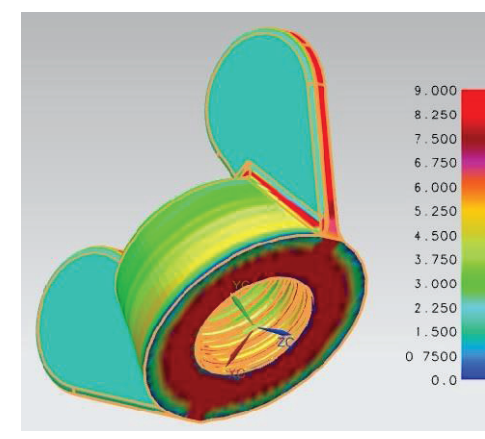

Figure 4. Wing Nut Drafting

Thick mass analysis is important to know the more mass accumulation regions. In such regions shrink cavities are possible, which is a type of defect. At such regions we 
should remove mass by making weight reduction pockets. But for wing nut such remedies are not possible considering strength as criteria. But the situation is not very critical as the region is tapered and in a very shallow region thick mass accumulation is there. Additionally, by increasing holding pressure also, shrink cavities can be avoided.

\section{Process Simulation}

Process simulation helps us to know proper gate position with respect to a component cavity, expected positions of vents, fill time, flow pattern, probable defects etc.

\section{A. Material Selection}

The materials selected for this work is PP and HDPE. Both are frequently available and widely used thermo plastics. PP is tough as well as flexible material while HDPE has superior mechanical properties. Their relative properties are enlisted in Table I.

TABLE I.

MATERIAL SPECIFICATION

\begin{tabular}{|l|l|l|}
\hline \multicolumn{1}{|c|}{ Material Properties } & \multicolumn{1}{c|}{$\mathrm{PP}$} & \multicolumn{1}{c|}{$\mathrm{HDPE}$} \\
\hline Density & $946 \mathrm{~kg} / \mathrm{m}^{3}$ & $970 \mathrm{~kg} / \mathrm{m}^{3}$ \\
\hline Softening Point & $150{ }^{\circ} \mathrm{C}$ & $125^{\circ} \mathrm{C}$ \\
\hline Formula & $\left(\mathrm{C}_{3} \mathrm{H}_{6}\right)_{\mathrm{n}}$ & $\left(\mathrm{C}_{2} \mathrm{H}_{4}\right)_{\mathrm{n}}$ \\
\hline Shrinkage & $1-2.5 \%$ & $1.5-3 \%$ \\
\hline Tensile Strength & $21-37 \mathrm{~N} / \mathrm{mm}^{2}$ & $19-39 \mathrm{~N} / \mathrm{mm}^{2}$ \\
\hline Injection Temperature & $260{ }^{\circ} \mathrm{C}$ & $240{ }^{\circ} \mathrm{C}$ \\
\hline Heat Deflection Temperature & $120^{\circ} \mathrm{C}$ & $90{ }^{\circ} \mathrm{C}$ \\
\hline Mold Temperature & $60^{\circ} \mathrm{C}$ & $30^{\circ} \mathrm{C}$ \\
\hline
\end{tabular}

\section{B. Process Parameter Selection}

Process parameters are selected from an injection molding machine specification. The motive behind this was validation of result obtained from simulation with the trial results of the component. The specification of the considered injection molding machine is mentioned in Table II.

TABLE II.

MACHINE SPECIFICATION

(TEXPLASST 1HD, MP LAB, CVRCE HYDERABAD)

\begin{tabular}{|l|l|}
\hline Shot Capacity & $2-45 \mathrm{gms} / \mathrm{shot}$ \\
\hline Plunger Diameter & $25 \mathrm{~mm}$ \\
\hline Stroke Length & $450 \mathrm{~mm}$ \\
\hline Clamping Capacity & $6.0 \mathrm{Tons}$ \\
\hline Injection Pressure & $80 \mathrm{~kg} / \mathrm{cm}^{2}$ \\
\hline Heating Capacity & $1.5 \mathrm{kw}$ \\
\hline Total Installed Power & $3.7 \mathrm{kw}$ \\
\hline Total Shut Height & $100-450 \mathrm{~mm}$ \\
\hline
\end{tabular}

\section{Simulation Results}

Based on the parameters discussed earlier, the flow analysis was run using Autodesk Mold Flow Adviser. The results were satisfactory and helpful for die design corresponding to the component. Fig. 5 represents die cavity filling stages in clockwise direction from top left corner. The preferred gating position and flow of material around internal helical thread profile can be observed in the figure. Input parameters are separately entered to run the simulation for PP and HDPE materials. The flow analysis results were further compared.

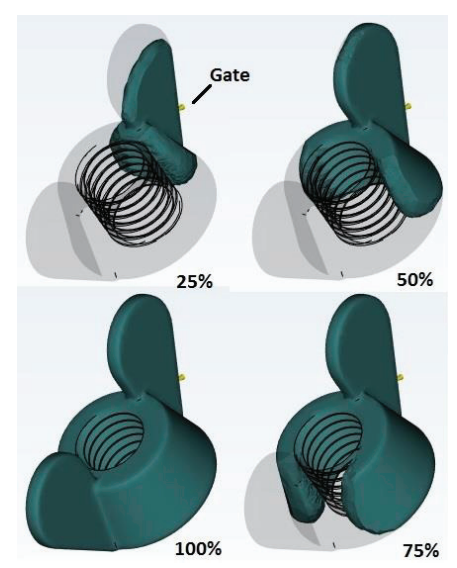

Figure 5. Plastic Flow in Mold Cavity

Confidence of fill and quality prediction results was compared and the same is represented in Fig. 6. With both the materials probability of filling the die is high but quality prediction is not very high. It is medium in thread region for HDPE but for PP quality prediction is average for entire component. This result indicates that HDPE is more suitable for making wing nuts as quality prediction reflects mechanical properties and appearance of a component.

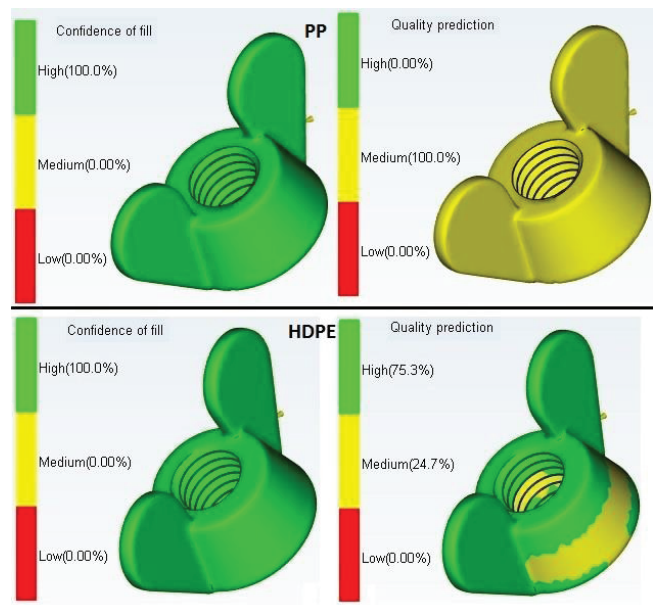

Figure 6. Confidence of Fill and Quality Prediction for PP( Top) and HDPE (Bottom)

The fill time estimated by the flow analysis indicates filling of cavity in 0.1 second with PP and 0.21 second for HDPE. This is quite possible as material flow in flow path is not considered. Additionally, shot volume is $2.32 \mathrm{~cm}^{3}$, total part weight is $1.71 \mathrm{~g}$ for PP and $1.76 \mathrm{~g}$ for HDPE. Fill time result is shown in Fig. 7.

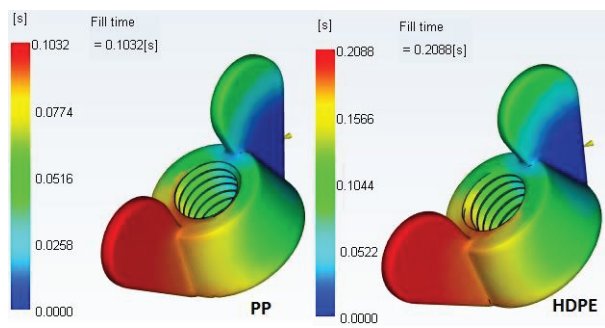

Figure 7. Fill Time 
The temperature variance result is represented in Fig. 8. This result helps us to identify areas with variable temperature so that cooling provision can be arranged accordingly. Maximum temperature is observed at thread region which can be further dissipated by threaded insert.

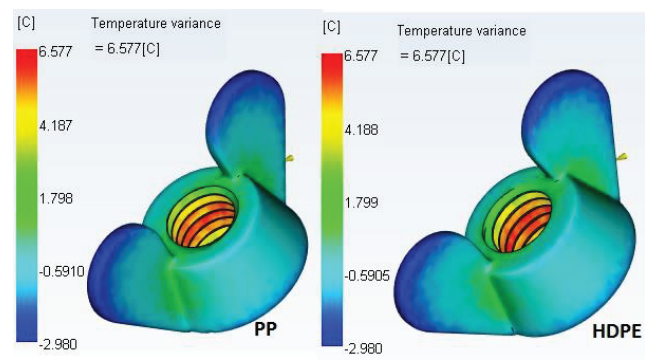

Figure 8. Temperature Variance

Temperature of flow front is indicated in Fig. 9. In case of both the materials the result is quite in agreement with assumption that the flow front should remain at high temperature so that complete filling of cavity can be ensured. Additionally, gate should solidify first so that directional solidification can be ensured and any back flow of material can be avoided. This also can be visualized in Fig. 9. This result is according to molding temperature of $\mathrm{PP}, 260^{\circ} \mathrm{C}$ and $\mathrm{HDPE}, 240^{\circ} \mathrm{C}$.

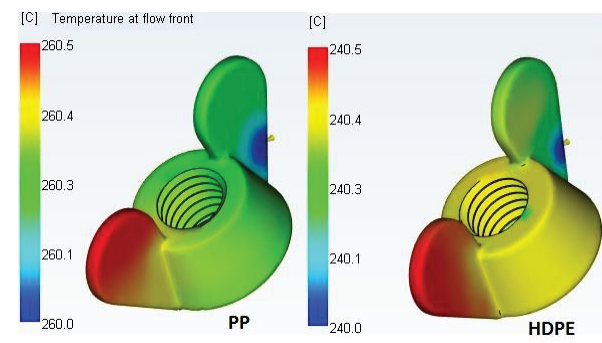

Figure 9. Temperature at Flow Front

It is important to know the time to reach ejection temperature. This is measured from the starting time of filling the mold cavity and helps to estimate cycle time of the injection molding process. Fig. 10 represents this time for both the material and the software estimates the cycle time in case of PP and HDPE as 30.04 second and 30.80 second respectively.

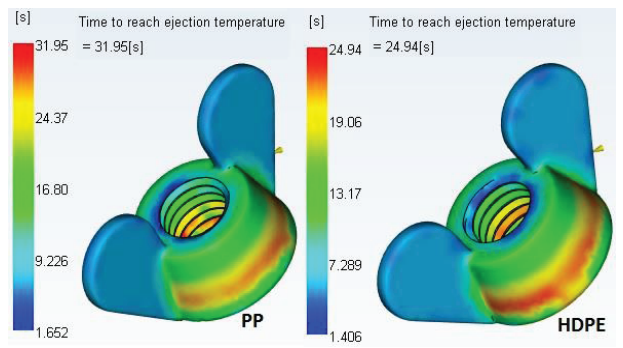

Figure 10. Time to Reach Ejection Temperature

Weld line indicates angle of overlap of material flow fronts. They are unavoidable if flow fronts splits while filling a cavity. In case of this mold cavity around the internal thread profile, material flow is diverging. This can be visualized from Fig. 5. Acute values of weld lines are acceptable and proper merger of flow fronts must be ensured by changing process parameters. Otherwise structural deficiency and surface imperfections are possible. To avoid weld lines, changing gate location, applying squeeze pressure, increasing melt temperature etc. can be attempted. Though there are smaller values of weld line angle for the component, we will apply squeeze pressure to overcome them as we are going to implement that for tackling shrink cavities. The weld line result with reference to both the materials in this work is shown in Fig. 11

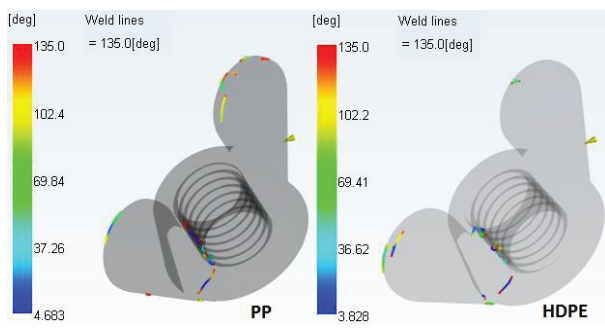

Figure 11. Weld Lines

The mold flow result indicates shrink cavities or sink marks also, as they were expected from thick mass analysis and shown in Fig. 4. Approximately same amount of sink mark was observed in thick mass region for both the materials, as shown in Fig. 12.

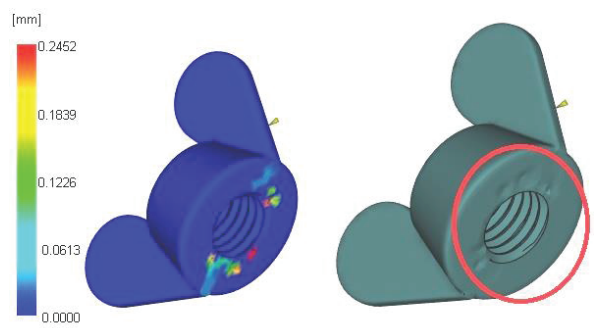

Figure 12. Sink Marks

The software indicated details of sink mark corresponding to both the materials which is shown in Table III. The amount of sink mark is minute but it can be avoided by making mass reduction pockets in that portion which is not advisable as per design and strength criteria of wing nut. We opt to apply squeeze pressure or packing pressure to overcome shrinkage cavities. There were no indications of warpage or any other type of defects.

TABLE III.

SINK MARK DETAILS

\begin{tabular}{|l|l|l|}
\hline \multicolumn{1}{|c|}{ Material Properties } & \multicolumn{1}{c|}{ PP } & \multicolumn{1}{c|}{ HDPE } \\
\hline Maximum Sink Depth & $0.25 \mathrm{~mm}$ & $0.25 \mathrm{~mm}$ \\
\hline Average Sink Mark Depth & $0.04 \mathrm{~mm}$ & $0.04 \mathrm{~mm}$ \\
\hline Model Prone to Sink Mark & $0.62 \%$ & $0.60 \%$ \\
\hline
\end{tabular}

\section{DiE Trial}

From the satisfactory flow analysis results, a die was modeled. This die was prepared only for trial purpose and is unlike the actual injection molding die which is prepared for industrial purpose. An injection molding die prepared for actual manufacturing process consists of proper provision of 
handling mismatch, mold cooling and ejection of the component. To achieve mass production, base on size of the component they are usually of multiple cavities.

\section{A. Mold Design}

The modeled die consisted single cavity and flow path. It has taper to take care of mismatch. No additional provision of mold cooling was given and ejection was also planned manually. The design was done considering ease of manufacturing. Based on overall volume of cavity runner length and diameter was taken from tool design parameter handbook from CITD. The assembly of modeled die is shown in Fig. 13 along with part and insert in its position. Runner of $4 \mathrm{~mm}$ diameter and $30 \mathrm{~mm}$ length can be observed, while gate diameter is $2 \mathrm{~mm}$ and it is $3 \mathrm{~mm}$ long. Taper on edges of core and cavity can be observed on the edges to avoid mismatch. Mold cavity and flow path are equally split in core and cavity.

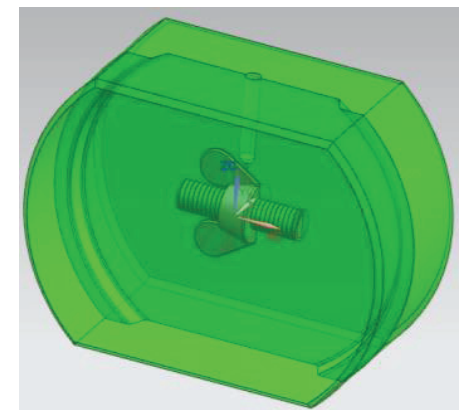

Figure 13. Model Mold

\section{B. Die Trial}

The model die was manufactured by EN 19 material. Overall shape was then turned at top and bottom. It was milled resting and aligning with feed system of injection molding machine. The part profile was cut by CNC milling with ball nose cutter. The trial was taken on injection molding machine at CVRCE as specified in Table II. Near to fifty shots were taken with PP and HDPE materials. The shot of first trial is shown in Fig. 14.

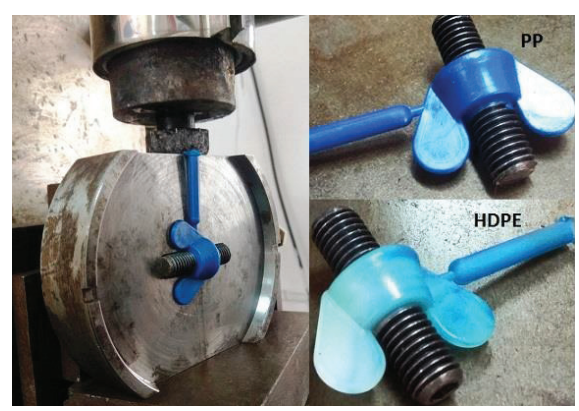

Figure 14. The Die Trial

Similarly, in the simulation results, there were no defects found on the component. There were no weld lines on the surface and no shrinking mark over the bottom portion of the molded wing nut. Additional holding pressure was applied in each shot to overcome shrinkage and the same can be visualized from Fig. 15.

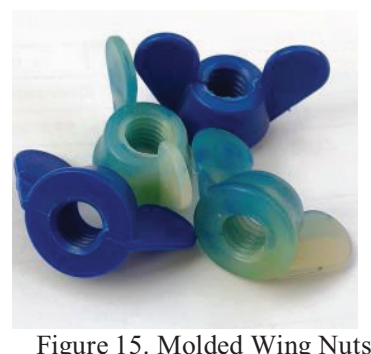

\section{Conclusions}

With recent advances in materials and manufacturing technology it is ultimately possible to process any material by any manufacturing process. One must always see economy and feasibility of the process. Wing nuts are usually made of metal and irrespective of their primary shaping process they must come across machining operation for obtaining internal thread profile. Multiple operations lead to high cost of manufacturing a component. In terms of economic and manufacturing feasibility it is advisable to make wing nuts by injection molding process. But based on strength criteria and related to end use of the product, application of wing nut made of polymer is limited to optimum strength, light weight and corrosion resistant applications. Scope of this work is limited to evaluating feasibility of making wing nuts by injection molding process using different polymers. Optimization of process parameters and molding wing nuts by a type of polymer with comparable properties of a metal can be further scope of research work.

\section{REFERENCES}

[1] R.Sánchez, A.Martinez, D.Mercado, A.CarbonelJ.Aisa, "Rapid heating injection moulding: An experimental surface temperature study", Polymer Testing, Volume 93, 2021, 106928

[2] Neeraj Kumar Jha, Bhavya Sri Tadiparthi, "Design and Analysis of the Sleeve Ejection System in Injection Molding Die for Trolley Wheel", CVRJST, Vol. - 17, pp. 132-137, 2019.

[3] Giovanni Lucchetta, Davide Masato, Marco Sorgato, "Optimization of mold thermal control for minimum energy consumption in injection molding of polypropylene parts", Journal of Cleaner Production,Vol.- 182, 2018, pp. 217-226.

[4] N. Sateesh, S. Devakar Reddy, G. Praveen Kumar, Ram Subbiah," Optimization of injection moulding process in manufacturing the flip cover of water meter", Materials Today: Proceedings 26, 2020, pp. 240-246.

[5] Abdulmecit Güldaş, Onuralp Uluer \& Ahmet Özdemir, "The Numerical Analysis of a Mold Cavity Filling Using the Finite Control Volume Method and Comparison to the Experimental Results", Polymer-Plastics Technology and Engineering, 48:4, 2009, pp. 389-396.

[6] Marton Huszar, Fawzi Belblidia, Helen M.Davies, Cris Arnold, David Bould, Johann Sien, "Sustainable injection moulding: The impact of materials selection and gate location on part warpage and injection pressure", Sustainable Materials and Technologies

Vol.- 5, 2015, pp. 1-8. 
[7] Jiseon Hong, Sun Kyoung Kim, Young-Hak Cho, "Flow and solidification of semi-crystalline polymer during microinjection molding", International Journal of Heat and Mass Transfer Vol.- 153, June 2020, 119576.

[8] Babur Ozcelik, Alper Ozbay, Erhan Demirbas, "Influence of injection parameters and mold materials on mechanical properties of ABS in plastic injection molding", International Communications in Heat and Mass Transfer, Vol.- 37, Issue 9, 2010, pp. 1359-1365.

[9] E.Farotti, M.Natalini, "Injection molding. Influence of process parameters on mechanical properties of polypropylene polymer. A first study", Procedia Structural Integrity, Vol.- 8, 2018,pp. 256-264.

[10] Neeraj Kumar Jha, P V Ramana, "Design Methodology and Analysis of Double Cavity Metal-Plastic-Insert Injection Molding Die for Push Board Pin”. CVRJST, Vol. - 14, pp. 9196, 2018.

[11] Simion Haragas, Ovidiu Buiga, Ovidiu Buiga, Claudiu Popa, Florina Maria , ȘerdeanFlorina, Maria Șerdean,” Demolding Moment Calculation for Injected Parts with Internal Saw Thread", MATERIALE PLASTICE, 2016, 53(3):378-381 